\title{
As xilanas nas propriedades de polpas marrons de eucalipto
}

\author{
Xylans on eucalyptus brown pulp propertie
}

\author{
Cristiane Pedrazzi $^{\text {* }}$ Jorge Luiz Colodette ${ }^{\text {II }}$ Rubens Chaves de OliveiraII \\ José Lívio Gomide ${ }^{\mathrm{II}}$ Vania Karine Dick Wille ${ }^{\mathrm{I}}$ Rodrigo Coldebella ${ }^{\mathrm{I}}$
}

\section{RESUMO}

\begin{abstract}
O objetivo deste estudo foi avaliar as propriedades de polpas kraft marrons de madeiras de Eucalyptus grandis $e$ Eucalyptus urograndis de composição química distinta, principalmente em relação aos seus conteúdos de xilanas, para fabricação de papéis. As polpas marrons de número kappa 17-18 e conteúdos de xilanas variando de 6 a $21 \%$ foram produzidas sob diferentes protocolos de cozimento: 1) kraft convencional; 2) pré-hidrólise kraft; 3) kraft de alta alcalinidade; e 4) kraft de alto rendimento. As polpas marrons foram refinadas em moinho PFI e seus respectivos papéis produzidos foram avaliados quanto às suas propriedades físico-mecânicas e ópticas. De modo geral, as propriedades de resistência dos papéis foram beneficiadas pelo conteúdo de xilanas. Para níveis muito altos de refino, ocorreram quedas bruscas de resistência ao rasgo para os papéis e o consumo de energia de refino foi influenciado pelo conteúdo de xilanas nas polpas marrons. Os mais altos valores de volume especifico aparente foram obtidos para os papéis com baixo conteúdo de xilanas, o que os torna interessantes, se branqueados, no segmento de papéis tissue. Os papéis com elevado conteúdo de xilanas apresentaramse economicamente atrativos e com características de resistências adequadas para o segmento de papéis de imprimir e escrever.
\end{abstract}

Palavras-chave: hemiceluloses, polpa de eucalipto, cozimento kraft, papel.

\section{ABSTRACT}

The objective of this study was to evaluate properties of brown pulp from Eucalyptus grandis and Eucalyptus urograndis of distinct chemical composition, mainly in refers to its xylans content, for the manufacture of tissue and printing and writing $(P \& W)$ paper grades. Brow pulps of kappa number 17-18 and xylans contents varying $6-21 \%$ had been produced under different cooking protocols: 1) conventional kraft; 2) pre-hydrolysis kraft; 3) high alkalinity kraft; and 4) kraft of high yield. The brown pulps had been beated in PFI mill and its respective produced papers had been evaluated as regards physical-mechanical and optic properties. The highest bulk values had been gotten for papers with low xylans contents, what had revealed interesting, if bleached, in the manufacture of tissue papers. The papers with high xylans contents, had been presented technically viable and with resistance characteristics adjusted for the manufacture of $P \& W$ papers.

Key words: hemicelluloses, eucalyptus pulp, kraft cooking, paper.

\section{INTRODUÇÃO}

O teor de hemicelulosesé uma característica importante das fibras de eucalipto, pois seu teor controla ou interfere em uma série de desempenhos operacionais e qualitativos na fabricação da celulose e do papel. A gestão das hemiceluloses permite diferenciar polpas, ganhar ou perder rendimentos de produção, melhorar ou piorar diversas propriedades das folhas de papel, etc (FOELKEL, 2009).

Nas madeiras do gênero Eucalyptus, a hemicelulose predominante é a O-acetil-4-Ometilglicuronoxilanas, a qual é polissacarídeo que consiste de aproximadamente 200 monômeros de $\beta$-D-xilopiranose unidos por ligações glicosídecas (14). Algumas unidades de xilose possuem uma cadeia lateral, consistindo de um resíduo de ácido 4-O-metil$\alpha$-D-glicurônico, ligado diretamente no carbono 2 da xilose. De cada dez unidades de xilose, sete contêm um grupo acetila ligado no $\mathrm{C}-2$ ou, mais frequentemente, no C-3. A presença dessa grande quantidade de grupos acetilas aumenta a solubilidade das xilanas não somente pelo aumento de polaridade, mas também pelo fato de tornar mais amorfa a estrutura dessas hemiceluloses (DANIELSSON \& LINDSTRÖM, 2005).

O processo de cozimento e branqueamento tem grande influência na quantidade e na estrutura

\footnotetext{
'Departamento de Ciências Florestais, Universidade Federal de Santa Maria (UFSM), 97105-900, Santa Maria, RS, Brasil. E-mail: cpedrazzi@terra.com.br. *Autor para correspondência.

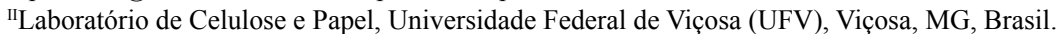


dos polissacarídeos remanescentes na polpa final, especialmente das hemiceluloses. De fato, mais da metade das hemiceluloses da madeira pode ser dissolvida no processo de cozimento e influenciar o consumo de reagentes químicos de branqueamento e a reversão de alvura das polpas (SIMÃO et al., 2004). As hemiceluloses também desempenham importante função no processamento e nas propriedades do papel, pois podem afetar importantes interações químicas entre fibras, água e outros produtos químicos utilizados na sua fabricação. De acordo com CHRISTIERMIN \& HENRIKSSON (2003), devido a maior afinidade com a água, as hemiceluloses favorecem o inchamento da fibra, tornando-a mais flexível. Isso aumenta a conformação das fibras durante a formação da folha de papel, melhorando e facilitando as ligações entre elas, produzindo papel de maior resistência. Grandes esforços têm sido feitos para determinar quais características influenciam mais ou menos nas propriedades do papel. Algumas características de grande relevância são a morfologia e a composição química das fibras. Enquanto a morfologia das fibras é fortemente influenciada pela qualidade da madeira, particularmente pela sua densidade, os seus teores de hemiceluloses sofrem grande efeito do processo de conversão da madeira em polpa. As xilanas são hemiceluloses facilmente removíveis em presença de álcali. Essa facilidade é atribuída à sua estrutura amorfa, pois contém grande quantidade de grupos ácidos que favorecem as reações dessas hemiceluloses com o hidróxido de sódio durante o processo kraft.

Fibras ricas em hemiceluloses tendem a produzir papel de alta densidade e menor volume, o que não é interessante para produtos tissue. Por outro lado, papéis de imprimir e escrever $(P \& W)$ precisam de força de tração e podem ser beneficiados por fibras com elevado conteúdo de hemiceluloses (SCHÖNBERG et al., 2001; ANJOS et al., 2005; MOLINA et al., 2008).

No segmento industrial produtivo, os papéis tissue demandam certas propriedades especiais, que os caracterizam com bom desempenho nas operações de suas máquinas de fabricação e em sua comercialização. Algumas dessas propriedades são: alto volume específico aparente, boa resistência do papel a seco e a úmido e alta porosidade e maciez. No caso de papéis de impressão, a resistência à tração indica a probabilidade de ruptura quando estes são sujeitos à tração exercida durante o processo de impressão, sendo desejados para esses papéis altos valores de índice de tração (D'ALMEIDA, 1988). Assim, o objetivo deste estudo foi avaliar as propriedades de polpas kraft marrons de madeiras de Eucalyptus grandis e Eucalyptus urograndis de composição química distintas, principalmente em relação ao conteúdo de xilanas para a fabricação de papéis. A avaliação baseou-se nas análises de propriedades físico-mecânicas e ópticas das polpas.

\section{MATERIAL E MÉTODOS}

Foram utilizadas amostras de polpas marrons denúmero kappa 17-18 de Eucalyptusgrandis e de um híbrido de Eucalyptus urophylla $\mathrm{x}$ Eucalyptus grandis (Eucalyptus urograndis) produzidas por quatro protocolos de cozimentos diferentes.

Os cavacos das madeiras foram sujeitos a diferentes processos de cozimentos, que resultaram em polpas de número kappa 17-18 e com conteúdos de xilanas variados. Os seguintes protocolos de cozimento foram utilizados: 1) kraft convencional; 2) kraft com pré-hidrólise; 3) kraft de alta alcalinidade; e 4) kraft de alto rendimento. No segundo e terceiro protocolos, as condições de cozimento foram ajustadas para resultarem em amostras de polpa com baixo conteúdo de xilanas $(\sim 8 \%)$. Já no primeiro e quarto protocolos, as condições foram controladas para obter polpas com conteúdo de xilanas normal (14$16 \%$ ) e elevado $(\sim 20 \%)$, respectivamente (Tabela 1$)$.

Ambos, tratamento da pré-hidrólise e todos os cozimentos kraft, foram realizados em um digestor M\&K com 1000 gramas de cavacos de madeira secos ao ar. No protocolo 2, os cozimentos foram realizados com o tratamento da pré-hidrólise. Este tratamento foi realizado antes do cozimento sob as seguintes condições para ambas as madeiras: licor $=$ apenas água; relação licor $/$ madeira $=4 / 1 \mathrm{~m}^{3} / \mathrm{t}$; temperatura $=170^{\circ} \mathrm{C}$; tempo até temperatura $=90 \mathrm{~min}$; tempo à temperatura $=5 \mathrm{~min}$. Após o tratamento da pré-hidrólise, realizou-se o cozimento kraft. Os procedimentos analíticos empregados para as análises das polpas foram: número kappa (TAPPI T $236 \mathrm{com}-$ 85), alvura (TAPPI T525 om-92), viscosidade (TAPPI T230 om-94), conteúdo de xilanas (TAPPI T249) e ácidos hexenurônicos, conforme metodologia desenvolvida por GELLERSTEDT \& LI (1996).

As polpas marrons foram então refinadas em moinho PFI, conforme a norma TAPPI 248 om00. A intensidade de refino foi expressa em graus Shopper-Rigler ( $\left.{ }^{\circ} \mathrm{SR}\right)$, segundo a norma TAPPI $200 \mathrm{sp}-01$. O número de revoluções foi variável, com a finalidade de obter três níveis de refino, que permitissem o desenvolvimento de curvas de refinação na faixa de 15 a $60^{\circ} \mathrm{SR}$. Foi utilizado o equivalente a $30 \mathrm{~g}$ de polpa absolutamente seca para cada nível de refino. As folhas foram formadas em formador tipo TAPPI, com gramatura de aproximadamente $60 \mathrm{~g} \mathrm{~m}^{-2}$, de acordo com a norma TAPPI 205 sp-02, e acondicionadas em ambiente climatizado, com temperatura de $23 \pm 1{ }^{\circ} \mathrm{C}$ e umidade relativa do ar de $50 \pm 2 \%$, para realização de testes físico-mecânicos e ópticos. As análises experimentais 
Tabela 1 - Condições utilizadas para produção das polpas marrons das madeiras de Eucalyptus grandis e Eucalyptus urograndis nos quatro protocolos de cozimento.

\begin{tabular}{|c|c|c|c|c|c|c|c|c|}
\hline Madeira & protocolo & sulfidez $(\%)$ & $\begin{array}{l}\text { licor/madeira } \\
\qquad\left(\mathrm{m}^{3} \mathrm{t}^{-1}\right)\end{array}$ & Temp. $\left({ }^{\circ} \mathrm{C}\right)$ & $\begin{array}{l}\text { tempo até } \\
\text { temp. (min) }\end{array}$ & $\begin{array}{l}\text { tempo à temp. } \\
\text { (min) }\end{array}$ & $\begin{array}{l}\text { Álcali Ativo } \\
\text { Total }\left(\mathrm{g} \mathrm{L}^{-1}\right)\end{array}$ & Fator $\mathrm{H}$ \\
\hline \multirow{4}{*}{ E. grandis } & 1 & 34 & $4 / 1$ & 170 & 90 & 40 & 20 & 724 \\
\hline & 2 & 34 & $4 / 1$ & 170 & 90 & 40 & 17,6 & 724 \\
\hline & 3 & 34 & $4 / 1$ & 151 & 90 & 22 & 74,2 & 92 \\
\hline & 4 & 34 & $4 / 1$ & 151 & 90 & 160 & 18,5 & 508 \\
\hline \multirow{4}{*}{ E. urograndis } & 1 & 34 & $4 / 1$ & 170 & 90 & 90 & 20 & 1.493 \\
\hline & 2 & 34 & $4 / 1$ & 170 & 90 & 90 & 17,6 & 1.493 \\
\hline & 3 & 34 & $4 / 1$ & 151 & 90 & 28 & 75,2 & 110 \\
\hline & 4 & 34 & $4 / 1$ & 151 & 90 & 360 & 18,5 & 1.111 \\
\hline
\end{tabular}

dos papéis foram realizadas seguindo metodologias padronizadas da norma TAPPI: gramatura (TAPPI 410 om-02), espessura (TAPPI 411 om-97), índice de rasgo (TAPPI 414 om-98), índice de tração (494 om-01), peso específico aparente (TAPPI $220 \mathrm{sp}$ 01), volume específico aparente (TAPPI $220 \mathrm{sp}-01$ ). As propriedades ópticas dos papéis, a opacidade e o coeficiente de dispersão de luz das folhas foram medidos em espectrofotômetro Datacolor, modelo Elrepho 450X, em três pontos da mesma folha, tomando-se as médias das leituras em cada nível de refino. As propriedades dos papéis foram relacionadas e avaliadas em função do consumo de energia requerida no refino das polpas. Os testes de resistência à tração foram realizados em aparelho de testes INSTRON, modelo 4204, com sistema computadorizado de análise e aquisição de dados, com distância entre garras de $100 \mathrm{~mm}$, velocidade de teste de $25 \mathrm{~mm} /$ min e capacidade da célula de carga de $1.000 \mathrm{~N}$.

\section{RESULTADOS E DISCUSSÃO}

Foi possível produzir polpas celulósicas de número kappa 17,0-17,6 com baixo (6-8\%), normal
(15-17\%) e alto (20-21\%) conteúdo de xilanas (Tabela 2) através de mudanças nas condições de cozimento (carga de álcali, temperatura e tempo). O cozimento com o tratamento da pré-hidrólise kraft (protocolo de cozimento 2) resultou em polpas com altas viscosidades, o que pode ser explicado pela remoção das hemiceluloses, que são macromoléculas de baixa massa molecular. Além disso, as polpas resultaram em valores de 6,0 e $6,4 \%$ de xilanas e de 14,6 e $16,5 \mathrm{mmol} \mathrm{kg}^{-1}$ de ácidos hexenurônicos para madeiras de Eucalyptus grandis e Eucalyptus urograndis, respectivamente, comprovando que as condições utilizadas no tratamento da pré-hidrólise kraft foram eficazes na remoção das xilanas. Os resultados obtidos neste estudo podem ser explicados por DANIELSSON (2007), o qual afirma que durante a polpação kraft uma série de processos de reações químicas e físicas ocorrem nas xilanas, como a dissolução, degradação e reposição nas fibras, conversão de grupos laterais e a clivagem destes na cadeia das xilanas. Segundo o autor, parte da xilana é solubilizada no meio reacional, ou após a degradação para pequenos fragmentos durante o

Tabela 2 - Principais características das polpas marrons produzidas pelos quatro protocolos de cozimento kraft das madeiras de Eucalyptus grandis e E. urograndis.

\begin{tabular}{|c|c|c|c|c|c|c|}
\hline Madeira & Protocolo & Número Kappa & Alvura (\%) & $\begin{array}{l}\text { Viscosidade } \\
\quad \text { (mPa.s) }\end{array}$ & Xilanas (\%) & $\begin{array}{c}\text { Ácidos } \\
\text { Hexenurônicos } \\
\left(\mathrm{mmol} \mathrm{kg}^{-1}\right)\end{array}$ \\
\hline \multirow{4}{*}{ E. grandis } & 1 & 17,6 & 41,0 & 63,2 & 15,2 & 61,8 \\
\hline & 2 & 17,2 & 34,9 & 117 & 6,0 & 14,6 \\
\hline & 3 & 17,1 & 41,1 & 17,4 & 7,0 & 31,7 \\
\hline & 4 & 17,0 & 36,7 & 79,2 & 20,2 & 63,4 \\
\hline \multirow{4}{*}{ E. urograndis } & 1 & 17,0 & 36,2 & 69,5 & 17,7 & 59,6 \\
\hline & 2 & 17,2 & 28,4 & 108 & 6,4 & 16,5 \\
\hline & 3 & 17,0 & 38,6 & 20,9 & 8,1 & 43,2 \\
\hline & 4 & 17,0 & 36,5 & 100 & 21,3 & 53,9 \\
\hline
\end{tabular}

Ciência Rural, v.45, n.9, set, 2015. 
período de aquecimento do cozimento. Ao final do processo de cozimento, parte dessa xilana dissolvida é readsorvida sobre as fibras. De acordo com SIMÃO et al. (2004), durante o cozimento kraft, os ácidos 4-O-metilglicurônicos (GlcA) sofrem degradação alcalina em consequência da degradação das cadeias de xilanas, podendo em parte reagir em meio alcalino, sendo convertidos em ácidos 4-deoxy-4hexenurônicos, por eliminação do grupo 4-O-metila. Os maiores valores de tração foram encontrados para os papéis com elevado conteúdo de xilanas $(20,2$ e 21,3\%, para madeiras de $\boldsymbol{E}$. grandis e $\boldsymbol{E}$. urograndis, respectivamente), ou seja, para os papéis produzidos com as polpas do protocolo de cozimento 4, os quais atingiram valores superiores a $80 \mathrm{Nm} / \mathrm{g}$ (Figura 1). $\mathrm{O}$ inverso foi observado para os papéis obtidos das polpas marrons dos protocolos de cozimento 2 e 3 , com conteúdo de xilanas variando de 6,0 a $8,1 \%$, que apresentaram valores baixos de resistência mecânica, quando comparado aos dos protocolos de cozimento 4 e referência 1. Segundo MOKFIENSKI et al. (2008), a viscosidade está relacionada com degradação das cadeias de carboidratos (celulose e hemicelulose) resultantes do cozimento. Sendo assim, como resultado da drasticidade do cozimento, as baixas viscosidades obtidas nas polpas do protocolo de cozimento 3 (Tabela 2) poderiam explicar os baixos valores de tração encontrados para os papéis produzidos a partir dessas polpas.

As hemiceluloses contribuem fortemente para as ligações intra e interfibras, resultando em papéis refinados mais resistentes à tração (MILANEZ et al., 1982), o que pode ser visto claramente neste estudo. Além disso, o consumo de energia para o refino das polpas com elevado conteúdo de xilanas (protocolo de cozimento 4) foi bastante inferior ao das demais polpas, mostrando que polpas com aproximadamente $20 \%$ de xilanas alcançam valores desejados de refino com considerável economia de energia para o processo. O refino é um tratamento mecânico realizado nas fibras de polpas celulósicas que tem por finalidade aumentar a flexibilidade e a ligação entre fibras, melhorando, consequentemente, as propriedades de resistência dos papéis produzidos (PUBLIO, 2012). Sendo assim, as polpas do protocolo de cozimento 4 necessitaram menor grau de refino que as polpas dos protocolos de cozimentos 2 e 3 , resultando nos menores consumos de energia.

Os maiores valores de índice de rasgo foram encontrados para os papéis com 15,2-17,7\%

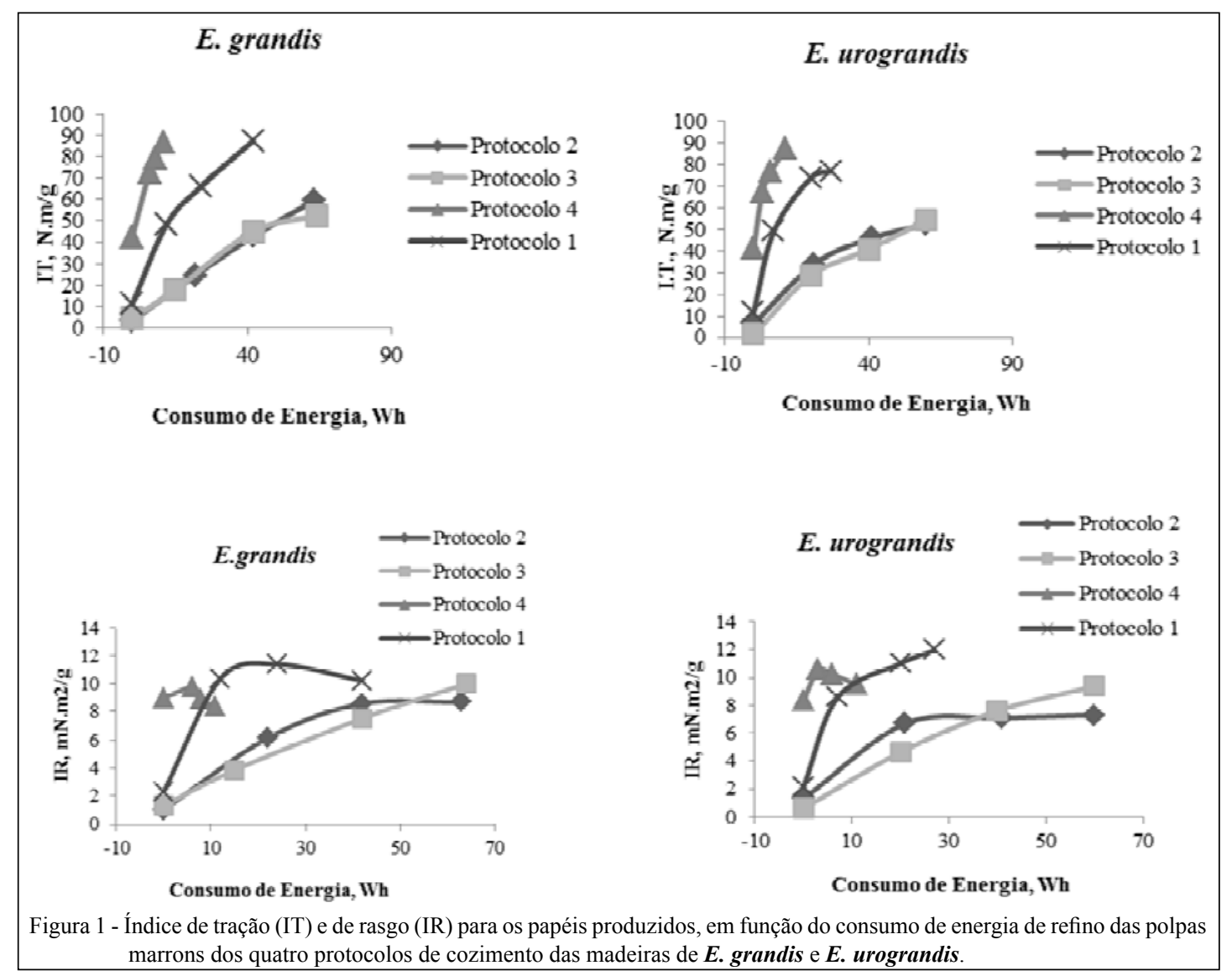

Ciência Rural, v.45, n.9, set, 2015. 
e 20,2-21,3\% de xilanas, obtidos das polpas marrons dos protocolos de cozimento 1 e 4 , respectivamente, indicando maior integridade das suas fibras (Figura 1). Os papéis com baixo conteúdo de xilanas $(6-8,1 \%)$, provenientes das polpas dos protocolos de cozimento 2 e 3, comportaram-se semelhantemente entre si.

Em níveis muito altos de refino, ocorreram, em geral, quedas bruscas de resistência ao rasgo para os papéis produzidos com as polpas dos protocolos de cozimento 1 e 4 , devido à ação de corte das lâminas do refinador, que causa a redução do comprimento médio das fibras, e também pela elevada porcentagem de hemiceluloses desses papéis, o que aparentemente fez agravar ainda mais a situação. SALOMÃO (2001) observou a mesma tendência em polpas refinadas de eucaliptos e pinus e afirmou que as hemiceluloses melhoram a ação do refino, mas, ao mesmo tempo, diminuiu a relação índice tração versus índice de rasgo, devido à diminuição no conteúdo proporcional de celulose.

Deve ser notado que as polpas do protocolo de cozimento 4 das madeiras de $\boldsymbol{E}$. grandis e $\boldsymbol{E}$. urograndis consumiram bem menos energia para o refino que as demais amostras, sendo os maiores índices de rasgo de 9,8 e $10,6 \mathrm{mN} \mathrm{m}^{-2} \mathrm{~g}^{-1}$ conseguidos com apenas 6 e 3 wh de energia, para as polpas de madeira de $\boldsymbol{E}$. grandis e $\boldsymbol{E}$. urograndis, respectivamente.

No segmento industrial produtivo, os papéis tissue e outros papéis porosos e volumosos demandam certas propriedades especiais, que os caracterizam com bom desempenho nas operações de suas máquinas de fabricação e em sua comercialização. Algumas dessas propriedades são: volume específico aparente, resistência do papel a seco e a úmido, porosidade, maciez, absorção de líquido, etc.

Os mais altos valores de volume específico aparente (VEA) foram obtidos nos papéis com baixo conteúdo de xilanas, ou seja, provenientes das polpas dos protocolos de cozimento 2 e 3 , o que os torna interessantes no segmento tissue, por apresentarem alto bulk e baixo teor de hemiceluloses (Figura 2). Para alguns tipos de papéis, os altos teores de hemiceluloses (acima de 16\%) podem não ser desejados: papéis

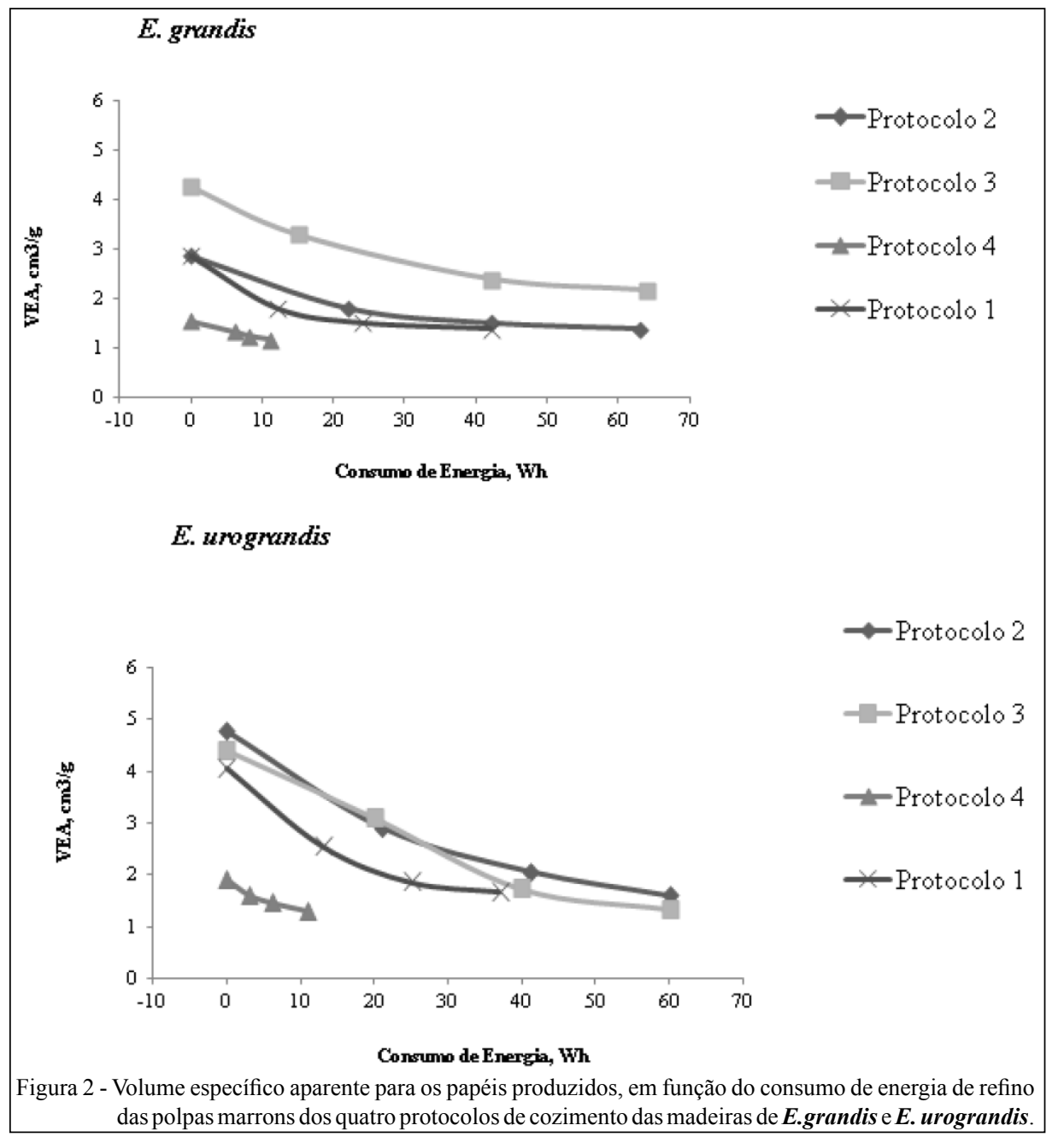

Ciência Rural, v.45, n.9, set, 2015. 
tissue, papéis decorativos, papéis-filtro, papéis base impregnação, etc., sendo a remoção de hemiceluloses uma possível alternativa (FOELKEL, 2007).

Para os papéis produzidos com as polpas marrons com conteúdo de xilanas de aproximadamente $20 \%$ (protocolo de cozimento 4), os valores de VEA foram muito baixos, assim como o consumo de energia das polpas utilizado para os três pontos de refino, mostrando novamente a influência das hemiceluloses sobre a eficiência do refino e na produção de papéis mais densos.

Aparentemente, os papéis obtidos das polpas dos protocolos de cozimentos 1, 2 e 3 apresentaram resultados semelhantes de opacidade, sendo os menores valores obtidos para os papéis provenientes do protocolo de cozimento 4 (Figura 3). De modo geral, o refino causou a queda na opacidade de todas as amostras, porém foi pouco influenciada pelo tipo de madeira.

Os papéis com baixo conteúdo de xilanas (produzidos com as polpas dos protocolos de cozimento 2 e 3 ) resultaram nos maiores valores do coeficiente de dispersão de luz (Figura 3). O oposto foi obtido para os papéis provenientes da polpa do protocolo de cozimento 4, que apresenta elevado conteúdo de xilanas (aproximadamente 20\%). Assim como para a opacidade, a propriedade de dispersão de luz foi pouco influenciada pelo tipo de madeira, o que pode ser verificado pelos valores semelhantes obtidos entre os papéis produzidos com as polpas marrons de E. grandis e de $\boldsymbol{E}$. urograndis. Além disso, em todas as amostras, como era esperado, o refino causou a queda nos valores do coeficiente de dispersão de luz.

\section{CONCLUSÃO}

De modo geral, as propriedades de resistência dos papéis marrons foram beneficiadas pelo aumento do conteúdo de xilanas, porém, para níveis muito altos de refino, ocorreram quedas bruscas de resistência ao rasgo. A redução no consumo de energia foi conseguida pelo aumento do conteúdo de xilanas nas polpas marrons. Se branqueadas, as polpas marrons com baixo conteúdo de xilanas seriam interessantes no segmento de papéis tissue, pois resultaram nos mais altos valores de volume específico aparente. As polpas com elevado conteúdo de xilanas apresentaram-se economicamente atrativas

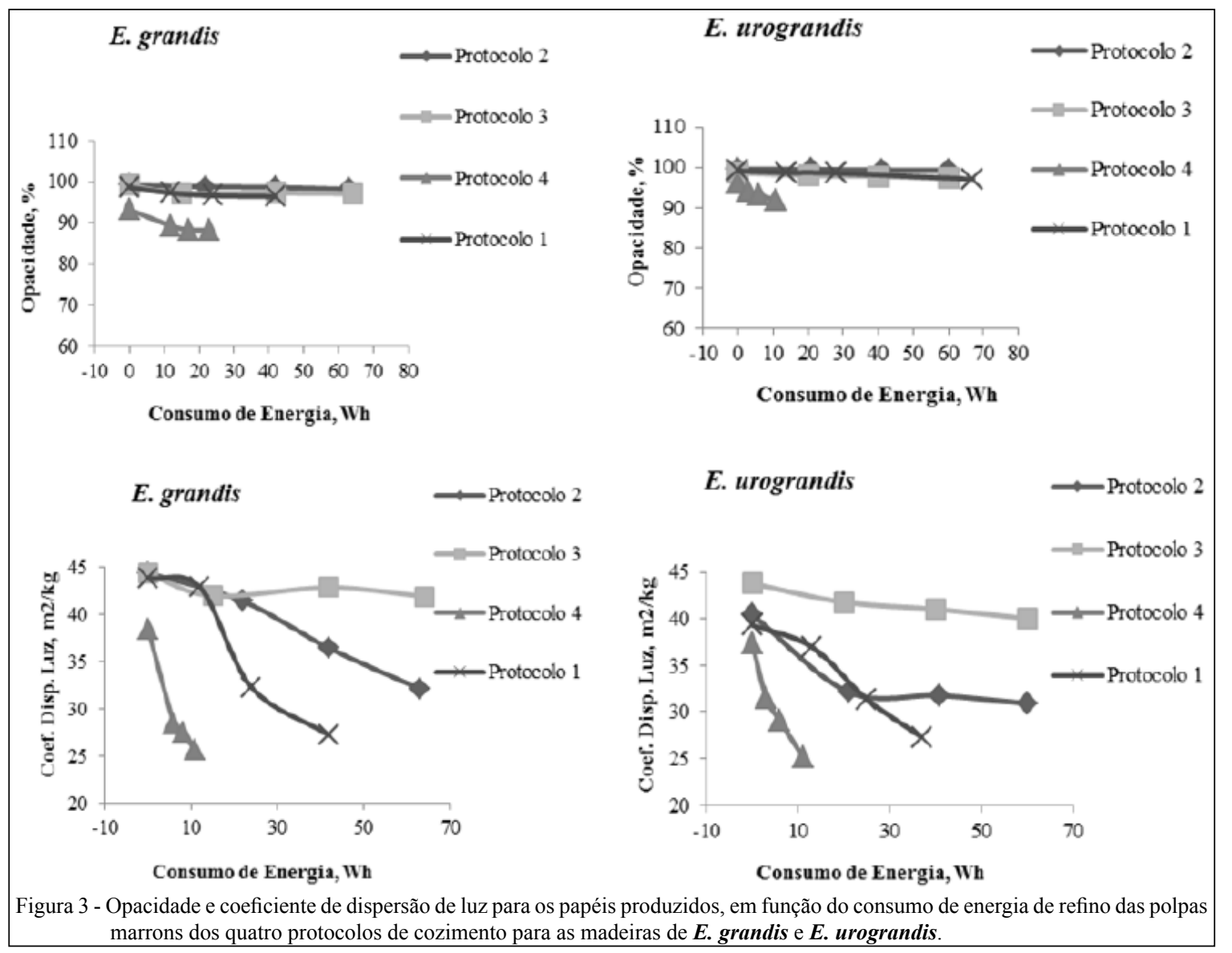

Ciência Rural, v.45, n.9, set, 2015. 
e com características de resistências adequadas para o segmento de papéis de imprimir e escrever.

\section{AGRADECIMENTOS}

Os autores agradecem ao Conselho Nacional de Desenvolvimento Científico e Tecnológico (CNPq) pelo apoio financeiro.

\section{REFERÊNCIAS}

ANJOS, O.etal. Efeitodoteordehemicelulosesnaqualidade dopapel produzido com fibra de Eucalipto. In: CONGRESSO FLORESTAL NACIONAL, 5. 2005, Portugual, Actas das comunicações... Portugual: Rui Silva e Fernando Páscoa Editores, 2005. 9p.

CHRISTIERNIN, M.; HENRIKSSON, G. Structure of hemicelluloses Pine kraft cooking liquors. In: INTERNATIONAL SYMPOSIUM ON WOOD AND PULPING CHEMISTRY, 2003, Sweden . Proceedings... Sweden: TAPPI, 2003. 8p.

DANIELSSON, S. Xylan reactions in kraft cooking. 2007. 73f. Doctoral Thesis in Pulp and Paper Technology - Department of Fibre and Polymer Technology, Royal Institute of Technology.

DANIELSSON, S.; LINDSTRÖM, M. Influence of birch xylan adsorption during kraft cooking and softwood pulp strength. Nord, Pulp Pap Res J, v.20, n.4, p.436-441, 2005.

D’ALMEIDA, M.L.O. Celulose e papel. Tecnologia de fabricação do papel. 2.ed. São Paulo: IPT, 1988. V.2, 403p.

FOELKEL, C.E.B. Propriedades papeleiras das árvores, madeiras e fibras celulósicas dos eucaliptos. In: Eucalyptus Online Book \& Newsletter, 2009. 111p. Online. Disponível em: <http://www. eucalyptus.com.br/eucaliptos/PT14_PropPapeleiras.pdf $>$. Acesso em: 18 mar. 2012.

FOELKEL, C.E.B. As fibras dos eucaliptos e as qualidades requeridas na celulose Kraft para a fabricação de papel. In: Eucalyptus Online Book \& Newsletter, 2007. 48p. Online.
Disponível em: <http://www.eucalyptus.com.br/capitulos/PT03 fibras.pdf $>$. Acesso em: 18 mar. 2012.

GELLERSTEDT, G.; LI, J. An HPLC method for the quantitative determination of hexenuronic acid groups in chemical pulps. Carbohydrate Research, v.294, p.41-51, 1996.

MILANEZ, A.P. et al. Influência das hemiceluloses nas propriedades óticas e físico-mecânicas da polpa. In: CONGRESSO ANUAL DA ABTCP, 15., 1982, São Paulo, SP. Anais... São Paulo: ABTCP, 1982. p.155-170

MOKFIENSKI, A. et al. Importância relativa da densidade da madeira e do teor de carboidratos no rendimento da polpa e na qualidade do produto final. Revista Ciência Florestal, v.18, n.3 p.401-413, 2008.

MOLINA, E.M.A. et al. Efecto de las xilanas en la refinabilidad y propiedades físico-mecánicas de pulpa kraft de eucalyptus spp. In:. CONGRESO IBEROAMERICANO DE INVESTIGACIÓN EN CELULOSA Y PAPEL, 2008, México. Anais... Guadalajara CIADICYP, 2008. 8p.

PUBLIO, R. Aplicações de celulases no refino de fibras celulósicas kraft branqueadas de eucalipto. 2012. 105f. Dissertação (Mestrado em Engenharia) - Universidade de São Paulo, SP.

SALOMÃO, K.G. Características e branqueabilidade de polpas kraft/ polissulfeto de eucalyptus e de pinus. 2001. $112 \mathrm{f}$. Dissertação (Mestrado em Ciência Florestal) - Universidade Federal de Viçosa, MG.

SCHÖNBERG, C. et al. The importance of xylan for the strength propertiesof sprucekraftfibres. Holzforscung, v.55,p.639-644,2001.

SIMÃO, J.P.F. et al. Cinética das reações dos ácidos metilglucurônicos e hexenurônicos no cozimento kraft de Eucalyptus globulus. In: CONGRESO IBEROAMERICANO DE INVESTIGACIÓN EN CELULOSA Y PAPEL, 2004, Córdoba. Anais... Córdoba CIADICYP, 2004. 8p.

TAPPI (TECHINICAL ASSOCIATION OF PULP AND PAPER INDUSTRY). TappiStandard Methods. Atlanta,2004-2005.1900p. 